\title{
Os impactos da existência de diversos mecanismos de solução de controvérsias na aplicação do Direito Internacional Ambiental ${ }^{*}$
}

\author{
Maitê de Souza Schmitz ${ }^{\star \star}$
}

\section{INTRODUÇÃO}

Atualmente, há mais de treze tribunais internacionais permanentes, além de pelo menos outros seis mecanismos de solução de controvérsias que operam em âmbito mundial. Apesar do considerável número de tais instituições, nunca se chegou a desenvolver, no Direito Internacional Público, um sistema compulsório de regras concernentes à concorrência de jurisdição de órgãos internacionais. Especificamente quando se trata da proteção ao meio ambiente, as disparidades entre as decisões de diferentes sistemas de solução de controvérsias demonstram a necessidade de alguma modificação no cenário internacional, a fim de melhor enfrentar as questões ambientais.

O presente artigo, desta forma, tratará dos impactos que a pluralidade de tribunais internacionais e outros mecanismos de solução de controvérsias exerce na aplicação do Direito Internacional Ambiental. Na Parte I, será apresentada a maneira através da qual diferentes tribunais e mecanismos

\footnotetext{
* Artigo apresentado como trabalho final para a disciplina de Direito Internacional Ambiental, ministrada pelo profesșor Stephen Kass, e cursada na Pace University, em 2003.

** Estudante do último ano de Direito na Universidade Federal do Rio Grande do Sul (UFRGS), também estudou na Pace University (New York), durante o segundo semestre de 2003, com uma bolsa da CAPES. A autora gostaria de agradecer à profa. dra. Cláudia Lima Marques pelo seu papel fundamental na concretização desse intercâmbio, pelo seu constante apoio, bem como pela oportunidade dada aos participantes de dividir com a comunidade acadêmica alguns dos resultados dessa experiência. Gostaria de agradecer, também, à CAPES pela oportunidade, ao prof. Kass pela ajuda e orientação, e à profa. dra. Catherine Tinker por todo o apoio dado durante o semestre em Nova Iorque.
} 
de solução de controvérsias (como a Corte Internacional de Justiça, os painéis da Organização Mundial de Comércio, as cortes de direitos humanos e os sistemas de solução de disputas do NAFTA e do MERCOSUL) lidam com a questão do meio ambiente.

Após comparar o tratamento dado ao meio ambiente por tais órgãos, verificando como as suas decisões enfrentam as questões de direito ambiental, a Parte II examinará as soluções já propostas para o problema do conflito de jurisdição desses órgãos internacionais, e se tais idéias seriam ou não viáveis. Finalmente, serão sugeridas algumas possibilidades de mudança no cenário internacional, para que seja melhor promovida a proteção ambiental. Nesse sentido, a melhor forma de atingir o referido fim-de melhor proteger o meio ambiente - seria através de mecanismos diplomáticos, com o foco na cooperação entre os Estados. Após, se, como última alternativa, as partes buscarem um mecanismo jurisdicional, a Corte Internacional de Justiça, atuando como órgão revisor, seria a instituição mais apropriada para decidir as questões ambientais.

\section{AS DIVERSAS MANEIRAS ENCONTRADAS PELOS ÓRGÃOS INTERNACIONAIS PARA TRATAR DA PROTEÇÃO AO MEIO AMBIENTE}

\section{A) A Corte Internacional de Justiça e as Cortes de Direitos Humanos \\ 1. A Corte Internacional de Justiça}

A Corte Internacional de Justiça (CIJ), o principal órgão jurídico das Nações Unidas,' não só tem jurisdição e competência ratione materiae para decidir disputas sobre questões ambientais, ${ }^{2}$ mas também é comumente incentivada a assim agir por significativa parcela da doutrina. ${ }^{3}$ Todavia, mesmo considerando o parco número de casos que são, via de regra, analisados pela $\mathrm{CIJ},{ }^{4}$ as questões ambientais são com pouquíssima frequiência levantadas, e

1 Carta da Organização das Naçôes Unidas, art. 92.

2 Veja Robert Jennings, The Role of the ICJ in the Development of International Environment Protection Law, 22 ENvTL. Pol. \& L. 312, 313 (1992).

3 Veja por exemplo World Commission on Environment and Development, Our Common Future 334 (1987); Catherine Tinker, "Environmental Security" in the United Nations: not a matter for the Security Council, 59 TENN. L. Rev. 787, 801 (1992).

4 Em média, a CIJ elabora, anualmente, cerca de duas a três decisões ou ordens. Veja Mark W. Janis, The Law of The Sea Tribunal, in International Courts For The Twenty-First Century 248 (Mark W. Janis ed. 1992) (fazendo uma análise comparativa entre o Tribunal Internacional de Direito do Mar e a CIJ). 
ainda mais raramente consideradas nas suas decisões.

Costuma-se citar o Caso Corfu Channel $^{5}$ como a primeira decisão da CIJ estabelecendo uma regra que poderia, posteriormente, vir a ser utilizada em casos envolvendo questões ambientais. ${ }^{6}$ Nesse caso, atribuiu-se responsabilidade ao Estado por sua falha em avisar aos demais acerca de um perigo iminente, bem como estabeleceu-se o dever do Estado de divulgar informações cujo desconhecimento possa acarretar efeitos danosos a outros países. Assim, entendeu-se, por analogia, que tais regras viriam a incluir os casos de poluição e riscos ambientais transfronteiriços. ${ }^{7}$ Embora tenha importância histórica, o caso Corfu Channel está longe de exercer um relevante papel no âmbito da proteção internacional do meio ambiente. Além de a palavra "meio ambiente" não ter sido mencionada em nenhuma parte da decisão, o resultado do caso foi obtido consideravelmente antes do desenvolvimento do direito internacional ambiental.
Os casos Nuclear Tests ${ }^{8}$ consistiram na primeira oportunidade que a CIJ teve de, efetivamente, abordar questões ambientais. O pedido da Austrália adotou uma tese similar à de "invasão" como base para determinar a responsabilidade da França, alegando que o depósito de material radioativo em seu território violaria sua soberania territorial. ${ }^{\circ}$ Embora a CIJ tenha determinado, preliminarmente, que a França deveria "evitar testes nucleares que causassem o depósito de material radioativo", ${ }^{10}$ não houve decisão de mérito, com base na declaração da França de que ela cessaria com os testes nucleares. ${ }^{11}$

Similarmente, no Case Concerning Phosphate Lands in Nauru, a CIJ novamente se restringiu à discussão quanto à admissibilidade, não tendo abordado a questão da proteção ambiental em sua decisão. ${ }^{12}$ A reabilitação das reservas de fosfato em Nauru, desgastada por ação da Austrália, foi reduzida a questões concernentes a, além de admissibilidade, responsabili-

5 Corfu Channel (UK v. Alb.), 1949 I.C.J. 4 (Apr. 9).

6 Ian Brownle, Principles of Public International Law 274 (Oxford 2003).

7 Ved P. Nanda \& George Rock Pring, International Environmental Law and Policy for the 21 st Century 73 (Ardsley ed. 2003).

8 Nuclear Tests (Australia v. Fr), 1973 I.C.J. 99 (Interim Protection Order of June 22); Nuclear Tests (N.Z. v. Fr.), 1973 I.C.J. 135 (Interim Protection Order of June 22).

9 Argument of Mr. Byers, Nuclear Tests (Australia v. France), 1973 I.C.J. Pleadings 479-90. 10 Nuclear Tests (Australia v. Fr), 1973 I.C.J. 99 (Interim Protection Order of June 22); Nuclear Tests (N. Z. v. Fr.), 1973 I.C.J. 135 (Interim Protection Order of June 22).

11 Nuclear Tests (Australia v. France), 1974 I.C.J. 253 (Dec. 20); Nuclear Tests (N. Z. v. Fr.), 1974 I.C.J. 457 (Dec. 20).

12 Case Concerning Phosphate Lands in Nauru (Nauru v. Australia), 1992 I.C.J. 240 (June 26). 
dade internacional e regime de exprotetorados da ONU. ${ }^{13}$ A opinião dissidente do vice-presidente, porém, destacou a importância da proteção ambiental no desenvolvimento ou na exploração dos recursos naturais. ${ }^{14}$

No Request for an Examination of Situation in Accordance with Paragraph 63 of Court's Judgment of 20 December 1974 in Nuclear Tests (Nova Zelândia v. França), ${ }^{15}$ a Nova Zelândia levantou diversos princípios ambientais para fundamentar seu pedido. Argumentando que o direito costumeiro evoluiu a ponto de compreender novos padrões e procedimentos de Direito Internacional Ambiental, a Nova Zelândia fundamentou no princípio da precaução o seu pedido de que a França deveria ter realizado um estudo de impacto ambiental dos testes nucleares em questão, antes de ter começado a levá-los a efeito. ${ }^{16}$ A Corte, novamente, não adentrou no mérito da questão, uma vez que considerou que o caso não se enquadrava nas hipóteses do Parágrafo 63 do julgamento anterior. ${ }^{17}$ Não obstante, a CIJ reconheceu a "obrigação de respeitar e proteger o meio ambiente". ${ }^{18}$ Outrossim, na sua opinião dissidente, o juiz Weeramantry destaca alguns princípios de direito ambiental mencionados pela Nova Zelândia, como o princípio da equiidade intergeracional (principle of intergenerational equity), ${ }^{19}$ o princípio

13 Ian Brownlie, Principles of Public International Law 274 (Oxford 6. ed.2003).

14 Case Concerning Phosphate Lands in Nauru (Nauru v. Australia), 1992 I.C.J. 240, 324-25 (June 26) (dissenting opinion of Judge Oda).

15 Request for an Examination of Situation in Accordance with Paragraph 63 of Court's Judgment of 20 December 1974 in Nuclear Tests (New Zealand v. France), 1995 I.C.J. 288 (Sep. 22).

16 A Nova Zelândia argumentava que, de acordo com o princípio da precaução, ao Estado que desejasse iniciar conduta potencialmente danosa ao meio ambiente recairia o ônus de provar que suas atividades não causariam contaminação ("the burden of proof fell on a State wishing to engage in potentially damaging environmental conduct to show in advance that its activities would not cause contamination"). Id. p. 298.

17 Id p. 307.

18 Id. p. 306.

19 O juiz Weeramantry, ao enfrentar a questão dos direitos intergeracionais, considerou o princípio da eqüidade intergeracional como um "princípio em desenvolvimento do direito ambiental contemporâneo" ("developing principle of contemporary environmental law"), e citou a afirmação de Lauterpacht de que "se um dano tal qual o alegado fosse causado ao meio ambiente por pessoas da Idade da Pedra, ele estaria ainda hoje entre nós" ("if damage of the kind alleged had been inflicted on the environment by the people of the Stone Age, it would be with us today"). Request for an Examination of Situation in Accordance with Paragraph 63 of Court's Judgment of 20 December 1974 in Nuclear Tests (New Zealand v. France) 1995 I.C.J. 288, 341 (Sep. 22) (dissenting opinion of Judge Weeramantry). 
da precaução (precautionary principle) ${ }^{20}$ e o reconhecimento, em geral, da necessidade de realização de estudos de impacto ambiental. ${ }^{21}$

Em uma Opinião Consultiva decidida em 1996, a CIJ teve a oportunidade de analisar algumas normas e princípios ambientais no âmbito do Direito Internacional. Em Legality of the Threat or Use of Nuclear Weapons, a Corte afirmou que os Estados têm um dever geral de garantir que atividades realizadas na esfera de sua jurisdição e controle respeitarão o meio ambiente não apenas de outros Estados, mas também de áreas fora do controle estatal. ${ }^{22}$

Mais recentemente, no caso Kasikili/Sedudu Island, o juiz Weeramantry apresentou outra opinião dissidente, expressando sua preocupação com relação aos aspectos ligados ao meio ambiente. No presente caso, a única referência ao meio ambiente feita na opinião majoritária foi para determinar que tanto os barcos de
Botswana quanto os da Namíbia que navegassem nos canais das Ilhas Kasikili/Sedudu poderiam estar sujeitos a regulamentações ambientais. ${ }^{23} \mathrm{O}$ que o juiz Weeramantry criticou, entretanto, foi o método adotado pela Corte para delimitar a fronteira: ao invés da divisão geométrica adotada pela maioria, o julgamento deveria ter levado em consideração "os interesses do ecossistema e da diversidade biológica", num esforço para preservar a reserva natural localizada na área em disputa. ${ }^{24}$

Finalmente, a CIJ tem, atualmente, uma oportunidade de versar diretamente sobre a proteção do meio ambiente, no julgamento adicional do Case Concerning the GabcikovoNagymaros Project. ${ }^{25}$ Tal controvérsia entre a Hungria e a Eslováquia permanece na lista de casos a serem decididos pela CIJ, embora já tenha sido analisado previamente pela Corte em 1997. ${ }^{26}$ Muitos consideram o Gabcikovo-Nagymaros Project o primeiro caso contencioso no qual a CIJ

20 Em suas palavras: "um princípio que está sendo cada vez mais defendido como parte do direito internacional do meio ambiente" ("a principle which is gaining increasing support as part of the international law of the environment"). Id. p. 342 .

21 Id. p. 344.

22 Legality of the Threat or Use of Nuclear Weapons (United Nations), 1996 I.C.J. 226, 241-2 (Jul. 08). 23 Case Concerning Kasikili/Sedudu Island (Botswana v. Namibia), 1999 I.C.J. 1045, 1107 (Dec. 13).

24 Case Concerning Kasikili/Sedudu Island (Botswana v. Namibia), 1999 I.C.J. 1045, 1184 (Dec. 13) (dissenting opinion of Judge Weeramantry).

25 International Court of Justice, Press Release 98/28, Sept 3 1998, disponível em http://www.icj-cij.org/icjwww/idocket/ihs/ihsframe.htm 26 Gabcikovo-Nagymaros Project (Hung. v. Slovakia), 1997 I.C.J. 7 (Sep. 25). 
claramente levantou questões ambientais em seu julgamento. ${ }^{27}$ De fato, a Corte procurou estabelecer um conceito para desenvolvimento sustentável,,$^{28} \mathrm{o}$ qual, embora não tenha sido considerado como um princípio pela $\mathrm{CIJ}$, foi tido como um fator para guiar a futura operação da usina de Gabcikovo. ${ }^{29}$ Contudo, o referido julgamento se concentrou quase totalmente no direito dos tratados, e em tópicos de responsabilidade do Estado em geral, ${ }^{30}$ não tendo reservado a devida atenção às questões ambientais apresentadas. Eis porque tal caso foi duramente criticado, haja vista sua falha em discutir diversos aspectos atuais do direito internacional ambiental. ${ }^{31}$ Ademais, na comprovação do "estado de necessidade ecológico" (state of ecological necessity), ${ }^{32}$ alegado pela Hungria como fator que a levou ao descumprimento do tratado com a Eslováquia, a CIJ estabeleceu o mesmo padrão elevado que exige na determinação do estado de necessidade tradicional. Com isso, a Corte deixou de considerar o princípio da precaução, ao menos nos casos de acordos e tratados já existentes. ${ }^{33}$

\section{As Cortes de Direitos \\ Humanos}

O juiz da CIJ Weeramantry, em um de seus votos, enfatizou a visão antropocêntrica na proteção ao meio ambiente, este considerado como précondição para a fruição de diversos direitos humanos, como o direito à

27 Afshin A-Khavari \& Donald R. Rothwell, The ICJ and the Danube Case: a missed opportunity for International Environmental Law?, 22 MeLB. U. L. REv. 507, 508 (1998).

28 Como notou a Corte, "a necessidade de conciliar o desenvolvimento econômico com a proteção do meio ambiente está expressa com propriedade no conceito de desenvolvimento sustentável" ("the need to reconcile economic development with protection of the environment is aptly expressed in the concept of sustainable development"). GabcikovoNagymaros Project (Hung. v. Slovakia) 1997 I.C.J. 7, 78 (Sep 25).

29 Id. p. 75-76.

30 Ian Brownle, Principles of Public International Law 274 (Oxford 6 ed. 2003).

31 Erika L. Preiss, The International Obligation to Conduct an Environmental Impact Assessment: the ICJ case concerning the Gabcikovo-Nagimarus Project, 7 N.Y.U. ENvTL. L. J. 307,308 (1999).

32 O Estado que levanta a hipótese de estado de necessidade deve provar que o ato, justificado por um interesse essencial do Estado ameaçado por um "perigo grave e iminente", era a "única forma" de garantir seus interesses, e não "prejudicava seriamente um interesse essencial" de outro Estado. Finalmente, o autor do ato não deve ter contribuído para causar o estado de necessidade. Gabcikovo-Nagymaros Project (Hung. v. Slovakia) 1997 I.C.J. 7, 40 (Sep. 25).

33 Ida L. Bostian. Flushing the Danube: the World Court's Decision Concerning the Gabcikovo Dam, 9 CoLO. J. INT'L ENvTL. L. \& PoL'y 401, 425 (Summer 1998). 
saúde e à vida. ${ }^{34}$ Esse é, normalmente, o enfoque adotado pelas Cortes de Direitos Humanos quando lidam com questões ambientais.

A Corte Européia de Direitos Humanos (CEDH) mencionou pela primeira vez a questão do meio ambiente no caso Powell \& Rayner v. Reino Unido, no qual ela procedeu ao balanço entre a necessidade da existência de um aeroporto e a poluição sonora por ele causada ao peticionário, tendo finalmente decidido pela manutenção do aeroporto. ${ }^{35}$ No ano seguinte, em um novo exercício de ponderação, a CEDH colocou novamente os aspectos ambientais em segundo plano, considerando, desse modo, que as restrições impostas pela Suécia à propriedade do peticionário (devido a normas de proteção ambiental) consistiam numa violação ao seu direito de propriedade. ${ }^{36}$

A preocupação quanto aos efeitos da poluição ao meio ambiente sobre o bem-estar da pessoa foi tema do caso Lopez Ostra v. Espanha: a CEDH determinou o pagamento de indenização ao peticionário pela violação, causada por danos ambientais, ao seu direito à privacidade. ${ }^{37}$ Do mesmo modo, no Guerra \& Outros v. Itália, ${ }^{38}$ a CEDH considerou que a Itália descumpriu suas obrigações ao deixar de garantir o direito à vida e à privacidade dos peticionários, entendendo que um alto grau de poluição ambiental pode afetar o bemestar do indivíduo, tendo conseqüências adversas em sua vida familiar e particular. ${ }^{39}$ Ainda, a CEDH entendeu que a Itália deveria ter informado às

34 Gabcikovo-Nagymaros Project (Hung. v. Slovakia), 1997 I.C.J. 7, 206 (Sep. 25) (dissenting opinion of Judge Weeramantry).

35 Powell \& Rayner v. United Kingdom, 12 Eur. Ct. H. R. 355, 369 (ser. A) (1990).

36 Fredin v. Sweden, 192 Eur. Ct. H.R. (Ser. A), 6 (1991).

37 Lopez Ostra v. Spain, App. No. 16798/90, 20 Eur. Ct. H.R. 277 (1994).

38 Guerra \& Others v. Italy, App. No. 14967/89, 26 Eur. Ct. H.R. 357, 367-83 (1998).

39 "In addition, in its report of 8 December 1988, a committee of technical experts appointed by the Manfredonia District Council said in particular that because of the factory's geographical position, emissions from it into the atmosphere were often channelled towards Manfredonia (see paragraphs 14-16 above). The direct effect of the toxic emissions on the applicants' right to respect for their private and family life means that Article 8 is applicable. The Court considers that Italy cannot be said to have "interfered" with the applicants' private or family life; they complained not of an act by the State but of its failure to act. However, although the object of Article 8 is essentially that of protecting the individual against arbitrary interference by the public authorities, it does not merely compel the State to abstain from such interference: in addition to this primarily negative undertaking, there may be positive obligations inherent in effective respect for private or family life (see the Airey v. Ireland judgment of 9 October 1979 , Series A no. 32, p. 17, § 32)." Guerra \& Others v. Italy, App. No. 14967/89, 26 Eur. Ct. H.R. 357, 367-83 (1998). Parágrafos 57-58. 
pessoas sobre os riscos de morar em local com tais problemas ambientais. Esse caso foi posteriormente diferenciado do McGinley \& Eagan v. Reino Unido, no qual os peticionários também requeriam a responsabilidade do Estado pelo descumprimento da obrigação de informá-los sobre os efeitos de testes nucleares que estavam sendo realizados na Christmas Island, onde os peticionários serviam às forças armadas. A Corte reiterou a ratio de Guerra \& Outros, embora tenha concluído que o Reino Unido forneceu as informações disponíveis, não tendo, portanto, violado as suas obrigações. ${ }^{40}$

A Corte Interamericana de Direitos Humanos nunca tratou diretamente com questões de proteção ambiental. A Comissão de Direitos Humanos, entretanto, já discutiu aspectos relacionados ao meio ambiente, ainda que tangencialmente, quando lidou com casos ligados aos direitos dos povos indígenas. ${ }^{41}$
B) Os painéis de solução de controvérsias do GATT/ OMC, do MERCOSUL e do NAFTA

\section{GATT/OMC}

Os fundamentos das decisões dos casos sob o Acordo Geral sobre Tarifas e Comércio (General Agreement on Tariffs and Trade - GATT) ${ }^{42}$ e sob a Organização Mundial do Comércio (OMC) tradicionalmente conflitaram com o direito internacional ambiental. ${ }^{43}$ As normas materiais do GATT/OMC não incluem os instrumentos internacionais voltados à proteção ambiental, os quais não fazem parte do GATT ou dos seus acordos. ${ }^{44}$ A maior parte das controvérsias surge devido a medidas de proteção ambiental adotadas por um Estado, ${ }^{45}$ as quais podem ser questionadas com base na cláusula da nação mais favorecida, ${ }^{46}$ na do tratamento nacional, ${ }^{47}$ ou nas proibições de restrições quantitativas a

40 McGinley \& Eagan v. United Kingdom, 27 Eur. Hum. Rts. Rep. 1 (1998).

41 See generally, Inara K. Scott, The Inter-American System of Human Rights: an Effective Means of Environmental Protection?, 19 VA. ENVTL. L.J. 197 (2000).

42 General Agreement on Tariffs and Trade, Oct. 30, 1947,61 Stat. A-11, T.I.A.S. 1700, 55 U.N.T.S. 194.

43 Virginia Dailey, Sustainable Development: Reevaluating the Trade vs. Turtles Conflict at the WTO, 9 J. TRANSNAT'L \& POL'Y $331,333$.

44 Lakshman D. Guruswamy, Should UNCLOS or GATT/WTO decide trade and environment disputes?, 7 MinN. J. Global TRADE 287, 288.

45 Para uma explicação geral sobre medidas comerciais empregadas para atingir propósitos ambientais, veja Charnovitz, The Environment v. Trade Rules: defogging the debate, 23 ENVTL. L. 475 (1993).

46 GATT art. I(1).

47 GATT art. III. 
importações. ${ }^{48}$ Dessarte, o que mais se discute é se as medidas adotadas pelos Estados estariam incluídas no rol de exceções listadas no artigo XX do GATT. ${ }^{49}$

Uma análise das decisões do GATT/ OMC demonstram que o meio ambiente tem um papel secundário, quando este conflita com interesses comerciais. $\mathrm{O}$ GATT com freqüência vedava ou restringia medidas comerciais empregadas para atingir propósitos ambientais, especialmente a proteção de recursos globais em comum (global common resources).$^{50}$ No caso Canadá-Herring and Salmon,,$^{51}$ por exemplo, o painel do GATT concluiu que a proibição de exportação, pelo Canadá, de certos tipos de salmão e arenque, devido à forma de conservação, não só violava o artigo $\mathrm{XI},{ }^{52}$ mas também não se incluía no rol de exceções do artigo XX (g) do GATT. ${ }^{53}$

Alguns anos após, o Painel do GATT teve a oportunidade de decidir duas vezes acerca da proibição de importação de atum, pelos Estados Unidos, de Estados que não seguissem as determinações contidas no Marine Mammal Protecion Act. ${ }^{54}$ A primeira decisão ${ }^{55}$ foi favorável ao pedido do México, concluindo que as proibições dos Estados Unidos eram restrições quantitativas (art. XI), e não se justificavam pelas exceções nem do artigo XX (b), nem do artigo XX (g) do GATT. ${ }^{56} \mathrm{~A}$ segunda objeção às restrições impostas pelos Estados

48 GATT art. XI.

49 GATT art. XX. Afirma, em parte: "[s]ubject to the requirement that such measures are not applied in a manner which would constitute a means of arbitrary or unjustifiable discrimination between countries where the same conditions prevail, or a disguised restriction on international trade, nothing in this Agreement shall be construed to prevent the adoption or enforcement by any contracting party of measures (...) (b) necessary to protect human, animal or plant life or health; $(. .).(\mathrm{g})$ relating to the conservation of exhaustible natural resources if such measures are made effective in conjunction with restrictions on domestic production or consumption".

50 Jeffrey L. Dunoff, Institutional Misfits: the GATT, the ICJ\& Trade-environment Disputes, 15 MiCH. J. INT'L L. 1043, 1053 (Summer 1994).

51 GATT Dispute Panel Report on Canada-Unprocessed Salmon and Herring, GATT B.I.S.D (35th Supp.) at 90 (1989).

52 ld. Parágrafo. 4.3

53 Id. Parágrafo. 5.1

54 16 U.S.C. $\S \S 1361-1362,1371-1384,1401-1407$ (1994 \& Supp.1995). The Marine Mammal Protection Act foi aprovado em 1972.

55 GATT Dispute Panel Report on United States Restrictions on Import of Tuna, 30 I.L.M. 1594 (1991).

56 Id. Parágrafo 6.2. O Painel concluiu que as medidas dos Estados Unidos não eram nem necessárias, nem primariamente direcionadas à conservação dos recursos naturais. Id. Parágrafos. 5.28, 5.33. 
Unidos foi trazida por países europeus que não barravam as importações de atum oriundas de Estados sujeitos à proibição direta dos Estados Unidos (e que, portanto, também eram prejudicados consoante o Marine Mammal Protection Act).${ }^{57} \mathrm{O}$ Painel modificou a decisão anterior no que tange à interpretação do artigo XX (b) e (g) do GATT. $^{58}$ Mesmo assim, o Painel não só rejeitou pela segunda vez a aplicação do artigo XX (g), ${ }^{59}$ mas também optou por não considerar documentos internacionais de direito ambiental na interpretação dos dispositivos do GATT. ${ }^{60}$

No âmbito da OMC, o caso Reformulated Gasoline representou outra objeção às regulamentações ambientais dos Estados Unidos. ${ }^{61}$ Nesse caso, o Órgão de Apelação, revertendo a justificativa do Painel, concluiu que as medidas impostas pelos Estados Unidos não preenchiam os requisitos do chapeau do artigo $\mathrm{XX}$ e, portanto, consistiam numa discriminação injustificada, bem como uma restrição velada ao comércio internacional. ${ }^{62}$ Similarmente, no caso Shrimp-Turtle, a proibição dos Estados Unidos à importação de camarão pescado através de métodos danosos a tartarugas marinhas foi também analisada segundo o chapeau do artigo $X X .{ }^{63}$ Nesse sentido, a decisão, favorável à Índia, à Malásia, ao Paquistão e à Tailândia, teve a mesma conclusão do caso Reformulated Gasoline ${ }^{64}$ Entretanto, esse caso foi considerado um avanço nas decisões da OMC acerca de proteção ambiental, ${ }^{65}$

57 GATT Dispute Panel Report on United States Restrictions on Import of Tuna, 33 I.L.M. 842(1994).

58 O Painel adotou um novo enfoque, segundo o qual as exceções contidas no art. XX (b) e (g) poderiam ser aplicáveis para a conservação de recursos naturais não-renováveis localizados aquém do território da parte. Id. Parágrafos. 5.10.

59 Id. Parágrafo 5.24.

60 ld. Parágrafos 5.18-5.20.

61 WTO Report of the Panel in United States - Standards for Reformulated and Conventional Gasoline (Treatment of Imported Gasoline and Like Products of National Origin), 35 I.L.M.274 (1996). 62 Id. p. 632-33.

63 United States-Import Prohibition of Certain Shrimp and Shrimp Products, WT/DS58R, May 15, 1998, reformado pelo Appellate Body Report, WT/DS58/AB/R, Oct. 12, 1998, disponivel em WTO Dispute Settlement (visited Feb. 22, 1999) < http://www.wto.org/wto/ dispute/distab.htm>. Parágrafos 116-119, 186-187.

64 Id. O Órgão de Apelação concluiu que a restrição no acesso ao mercado norte-americano baseada somente na adoção de determinadas políticas por governos estrangeiros consistiria em discriminação injustificada. Id. Parágrafos 7.25, 7.26, 7.49, 7.62.

65 Ved P. NANDA \& George Rock PRING, International Environmental Law and Policy for the 21st Century. 413 (Ardsley ed. 2003). 
não somente porque reconheceu a importância da proteção ambiental, mas também porque estabeleceu "um novo padrão de revisão de medidas comerciais que visem à proteção de recursos ambientais globais". ${ }^{66}$

\section{MERCOSUL e NAFTA}

\section{Mercosul}

As fontes nas quais o Tribunal Arbitral do MERCOSUL pode basear suas decisões consistem em tratados e documentos subseqüentes (ordenamento jurídico do Mercosul), e princípios gerais do Direito Internacional, bem como, mediante autorização das partes, em eqüidade. ${ }^{67}$ Diferentemente do NAFTA, porém, o MERCOSUL não tem um acordo específico que seja diretamente voltado à proteção ambiental. Embora expressamente mencionada no preâmbulo do Tratado de Assunção, ${ }^{68}$ a proteção do meio ambiente ainda se restringe ao campo da declaração de princípios, carecendo da força necessária para ser aplicado. ${ }^{69}$ Outrossim, a afirmação contida no preâmbulo não consiste sequer em um objetivo, mas sim em uma preocupação com relação ao desenvolvimento de uma área de livre comércio, já que as regulamentações ambientais poderiam acabar por restringir o comércio entre as partes. ${ }^{70}$

A lógica que considera o meio ambiente como um elemento secundário ${ }^{71}$ e que, portanto, visa a proteger o

66 Patricia Isela Hansen. Transparency, Standards of Review, and the Use of Trade Measures to Protect the Global Environment, 39 VA. J. INT'L L. 1017, 1057 (Summer 1999). 67 Protocolo de Brasília para a Solução de Controvérsias, MERCOSUL/CMC/DEC. N 01/ 1991 art. 19.

68 O Preâmbulo do Tratado de Assunção assim estabelece: "Considerando que a ampliação das atuais dimensões de seus mercados nacionais, através da integração constitui condição fundamental para acelerar seus processos de desenvolvimento econômico com justiça social; Entendendo que esse objetivo deve ser alcançado mediante o aproveitamento mais eficaz dos recursos disponíveis, a preservação do meio ambiente, o melhoramento das interconexões físicas, a coordenação de políticas macroeconômicas da complementação dos diferentes setores da economia, com base nos princípios de gradualidade, flexibilidade e equilíbrio". Tratado para a Constituição de um Mercado Comum Entre a República Argentina, a República Federativa do Brasil, a República do Paraguai e a República Oriental do Uruguai (Assunção, 26/03/1991).

69 Guillermo Malm Green. Environmental Issues and MERCOSUR, in Free Trade Area for the Americas. 184 (Joseph A. McKinney \& Melissa Essary eds. 1995).

70 JuAn Novara. Integracion Economica, Comercio Internacional y Medio Ambiente: Ensenanzas para el MERCOSUR. 98, 110 (1994).

71 Jonathan S. Blum, The FTAA and the Fast Track to Forgetting the Environment: a comparison of the NAFTA and the MERCOSUR Environmental Models as Examples for the Hemisphere. 35 TEX. INT'L L.J. 435. 
sistema comercial das conseqüências advindas de um meio ambiente adverso (e não o contrário), ${ }^{72}$ também está refletida nos dois únicos casos decididos pelo Tribunal Arbitral que lidam, ainda que indiretamente, com questões ambientais. ${ }^{73} \mathrm{O}$ primeiro caso é o Laudo VI do Tribunal Arbitral do MERCOSUL, de 2002, que decidiu sobre a controvérsia apresentada pelo Uruguai ao Brasil sobre a "Proibição de Importação de Pneumáticos Remoldados Procedentes do Uruguai". No presente caso, o Uruguai contestava a Portaria $\mathrm{N}^{\circ} 8 / 00$, de 25 de setembro de 2000, da Secretaria de Comércio Exterior do Ministério de Desenvolvimento, Indústria e Comércio Exterior (SECEX) do Brasil, a qual "dispôs a não concessão de licenças de importação de pneumáticos recauchutados e usados, classificados na posição 4012 da Nomenclatura Comum do MERCOSUL (NCM), seja para consumo ou uso como matéria-prima". O Uruguai alegava que tal restrição imposta às importações de pneumáticos remoldados constituía-se numa nova barreira ao comércio, contrária aos propósitos do MERCOSUL. O Brasil aduziu, por sua vez, que um pneumático remoldado não poderia ser considerado como um pneumático novo, uma vez que apenas $30 \%$ dele seria composto de material novo. Além disso, por ser impossível reformar novamente tais pneumáticos, após sua vida útil, eles acabariam se transformando, ao final, num "resíduo indesejável". ${ }^{74} \mathrm{O}$ Tribunal Arbitral entendeu que a regulamentação do governo brasileiro que proibia a importação de pneumáticos remoldados do Uruguai era incompatível com a normativa MERCOSUL, pois consistia numa medida restritiva ao comércio recíproco existente. Conseqüentemente, determinou-se que o Brasil deveria adaptar sua legislação interna em consideração à referida incompatibilidade. ${ }^{75}$

O segundo caso consiste no Laudo VII do Tribunal Arbitral, de 2002, o qual decidiu sobre a controvérsia apresen-

72 Leila Devia, La Politica Ambiental en el Marco del Tratado de Asuncion, in MERCOSUR y MEdio AmBiente 27, 29-30 (Ediciones Ciudad Argentina.ed. 1996).

73 Tal número é significativo, já que o Tribunal Arbitral só decidiu, até o presente momento, nove casos. Além disso, o mecanismo de solução de controvérsias do MERCOSUL não prevê casos específicos de direito ambiental. See, David Lopez, Dispute Resolution Under MERCOSUR from 1991 to 1996: Implications for the Formation of a Free Trade Area of the Americas, 3 NAFTA: L. \& Bus. Rev. Am. 3, 20 (1997).

74 Laudo do Tribunal Arbitral ad Hoc do MERCOSULConstituído para Entender da Controvérsia Apresentada pela República Oriental do Uruguai à República Federativa do Brasil sobre "Proibição de Importação de Pneumáticos Remoldados (Remolded) Procedentes do Uruguai" (Uruguai v. Brasil), 2000, disponivel em http:// www.mercosur.org.uy/portugues/snor/normativa/laudos.htm\#neumaticos. 
tada pela Argentina ao Brasil sobre "obstáculos à entrada de produtos fitossanitários argentinos no mercado brasileiro" e a "não incorporação das Resoluções GMC N $\mathrm{GM}^{\circ}$ 48/96, 87/96, 149/ 96, 156/96 e 71/98, o que impede sua entrada em vigência no MERCOSUL." A Argentina reclamava dos obstáculos derivados da imposição de restrições originárias de registro para os produtos fitossanitários, resultando numa barreira à importação de produtos da Argentina. ${ }^{76} \mathrm{O}$ Brasil, por sua vez, argumentou que o tratado de Assunção não proibia a adoção de medidas unilaterais necessárias para a proteção da saúde, do meio ambiente e da segurança da população. Alegou, ademais, que o sistema de registro para produtos fitossanitários existente no Brasil não era discriminatório, já que era aplicado igualmente tanto para as indústrias nacionais quanto para as estrangeiras. ${ }^{77} \mathrm{O}$ Tribunal Arbitral, entretanto, concluiu que o Brasil estava violando seu dever de promover a livre circulação de mercadorias no
MERCOSUL, pois considerou que a restrição supracitada era por demais ampla, ao invés de ser direcionada para produtos determinados. Assim sendo, o Tribunal Arbitral determinou que o Brasil deveria incorporar a seu ordenamento jurídico interno as Resoluções GMC No 48/96, 87/96, 149/96, 156/96 e $71 / 98$, e, caso fosse necessário, "adotar as medidas e ditar as normas jurídicas internas que garantam a efetiva aplicação destas normas". ${ }^{78}$

\section{NAFTA}

O preâmbulo do Tratado de Livre Comércio da América do Norte (North American Free Trade Agreement NAFTA) se refere expressamente ao meio ambiente, estabelecendo como metas promover o desenvolvimento sustentável, bem como reforçar a elaboração e a aplicação de leis e regulamentos em matéria ambiental. ${ }^{79}$ As instituições referentes ao meio ambiente do NAFTA foram consideradas mais "sofisticadas" do que aquelas do MERCUSUL, ${ }^{80}$ enquanto

76 Laudo Arbitral do Tribunal Arbitral "ad Hoc" do Mercosul Constituído para Decidir sobre a Controvérsia Apresentada pela República Argentina à República Federativa do Brasil sobre "Obstáculos à entrada de produtos fitossanitários argentinos no mercado brasileiro. Não incorporação das Resoluções GMC No 48/96, 87/96, 149/96, 156/96 e 71/98, o que impede sua entrada em vigência no MERCOSUL", 2002, disponivel em http:// www.mercosur.org.uy/portugues/snor/normativa/laudos.htm\#fitosanitario.

77 Id.

78 Id.

79 North American Free Trade Agreement, 32 I.L.M. 297.

80 Pedro Villegas. Nature beyond the nation state symposium: the environmental challenge of the common market in South America: REMA under MERCOSUR, 29 GOLDEN GATE U.L. REv. 445 (Spring 1999). 
os dispositivos do NAFTA foram tidos como mais "favoráveis ao meio ambiente" do que as regras da OMC. ${ }^{81}$

O NAFTA contém três mecanismos de solução de controvérsia: o Capítulo XI (arbitragem internacional para os casos em que investidores estrangeiros reclamem de violações às disposições do NAFTA referentes a investimentos), ${ }^{82}$ o Capítulo XIX (solução de controvérsias em matéria de anti-dumping e direitos compensatórios) ${ }^{83}$ e o Capítulo XX (interpretação, aplicação ou violação do NAFTA) ${ }^{84}$ Os dispositivos mais controvertidos do NAFTA são os procedimentos do Capítulo XI, os quais levantaram diversas preocupações ambientais. ${ }^{85} \mathrm{O}$ temor de que o artigo 1110 do NAFTA possa ser utilizado para forçar governos a pagar indenizações pela aplicação de regulamentações ambientais aumentou após a decisão Metalclad, ${ }^{86}$ na qual o México foi condenado a indenizar a Metalclad em US\$16.685.000. Isso porque entendeuse que a negativa do Município de Guadalcazar (no México) em conceder licença municipal para a construção de um depósito permanente (aterro sanitário) de resíduos perigosos, tendo como justificativa a proteção ambiental, consistia em falha do México em fornecer à Metalclad tratamento justo e eqüitativo. ${ }^{87}$ Atualmente, há, ainda pendentes, cerca de onze casos

81 Greg Block. Trade and environment in the western hemisphere: expanding the North American Agreement on Environmental Cooperation into the Americas, 33 ENVTL. L. 501 (Summer 2003).

82 NAFTA art. 1116(1). Veja por todos, Daniel M. Price. An Overview of the NAFTA Investment Chapter: Substantive Rules and Investor-State Dispute Settlement, 27 INT'L LAW. 727, 731-2 (1993).

83 NAFTA arts. 1901-11.

84 NAFTA arts. 2001-22. Veja por todos, Gary N. Horlick \& F. Amanda DeBusk, Dispute Resolution Under NAFTA: Building on the U.S.-Canada FTA, GATT and ICSID, $10 \mathrm{~J}$. INT'L ARB. 51, 64 (1993).

85 Howard Mann \& Konrad von Moltke, International Institute for Sustainable Development, NAFTA's Chapter 11 and the Environment: Addressing the Impacts of the Investor-State Process on the Environment 1, 38 (1999), disponivel em http:// iisd.ca/pdf/nafta.pdf.

86 Vicki Been, The global fifth amendment? Nafta's investment protections and the misguided quest for an international "regulatory takings" doctrine, 78 N.Y.U. L. REv. 30, 33-34. A autora afirma que "disposições muito idênticas ao art. 1110 do NAFTA estão contidas em muitos dos 1500 tratados bilaterais de investimento, em vigor em todo o mundo" ("provisions nearly identical to NAFTA's article 1110 are contained in many of the 1500 bilateral investment treaties in effect around the world").

87 Metalclad v. United Mexican States, ICSID Case No. ARB(AF)/97/1 Final Award, p. 74 (Aug. 30, 2000), disponivel em http:// www.state.gov/s/1/c3752.htm. 
estabelecidos consoante o capítulo XI, em que são questionadas regulamentações ambientais e de uso da terra. ${ }^{88}$

Em outro caso, a proibição, imposta pelo Canadá, de importação e venda de MMT, uma substância tóxica, foi questionada por uma companhia norteamericana. ${ }^{89} \mathrm{O}$ Canadá aceitou fazer um acordo nesse caso, mas, caso tivesse seguido adiante na contenda, a sua atitude seria provavelmente considerada como uma violação do artigo 1105 do NAFTA, referente ao dever de tratamento justo e eqüitativo. ${ }^{90}$ Do mesmo modo, no caso S.D. Myers, o Tribunal, seguindo praticamente a mesma lógica do Metalclad, considerou que a proibição de exportação de resíduos de

88 Notice of Arbitration and Statement of Claim Under the Arbitration Rules of the United Nations Commission on International Trade Law and the North American Free Trade Agreement (Frank v. United Mexican States) (Aug. 5, 2002), disponivel em http://www.dfait- maeci.gc.ca/tna-nac/NoticeofArbitration l.pdf; Notice of Arbitration and Statement of Claim (Canfor Corp. v. United States) (July 9, 2002), disponivel em http:// www.state.gov/documents/organization/13203.pdf; Notice of Intent to Submit a Claim to Arbitration Under Section B of Chapter 11 of the North American Free Trade Agreement (Doman Indus. Ltd. v. United States) (May 1, 2002), disponivel em ht tp://www.international-economic-law.org/US\%20 Notices/ Doman\%20Notice\%C20of\% 20Intent.pdf; Submission to Arbitration (GAMI Investment, Inc. v. United Mexican States) (Apr. 9, 2002), disponivel em http:// www.state.gov/documents/organization/11848.pdf; Notice of Intent to Commence Arbitration Pursuant to Chapter XI of the North American Free Trade Agreement (Calmark Commercial Dev., Inc. v. United Mexican States) (Jan. 11, 2002), disponivel em http://www.international-economic-law.org/Mexicans/ Calmark_Redacted_NOI.pdf; Notice of Intent to Submit a Claim to Arbitration Under Section B of Chapter Eleven of the North American Free Trade Agreement (Crompton Corp. v. Canada) (Nov. 6, 2001), disponivel em http://www.dfait-maeci.gc.ca/tna-nac/ ComptonCorp.pdf; Notice of Arbitration Under the Rules Governing the Additional Facility for the Administration of Proceedings by the International Centre for Settlement of Investment Disputes and the North American Free Trade Agreement (Fireman's Fund v. United Mexican States) (Oct. 30, 2001), disponivel em http:// www.dfait-maeci.gc.ca/tna- nac/documents/Fireman_Notice.pdf; Notice of Arbitration (Adams v. United Mexican States) (Feb. 16, 2001), http://www.international-economiclaw.org/Mexicans/Adams\%20et\%C20al\%C20and\%C20Mexico\%C20\%20$\% 20$ Notice $\% 20$ of $\% 20$ Arbitration.PDF; Notice of Arbitration (Karpa v. United Mexican States) (Apr. 30, 1999), at http://www.state.gov/documents/organization/3995.pdf; Notice of Claim (Loewen Group, Inc. v. United States) (Oct. 30, 1998), disponivel em http://www.state.gov/documents/organization/3922.pdf.

89 Ethyl Corporation v. Canada, 38 I.L.M. 708.

90 David A. Gantz, Potential Conflicts Between Investor Rights and Environmental Regulation Under NAFTA's Chapter 11, 33 GeO. WASh. INT'L L. REv. 651, 665-666 (2001). 
PCB pelo Canadá consistia em violação ao artigo 1105 do NAFTA, rejeitando, portanto, a alegação do Canadá de que tal medida visava ao cumprimento de diversos acordos internacionais de proteção ao meio ambiente. ${ }^{9 !}$

As controvérsias estabelecidas sob o capítulo XIX também podem afetar a proteção do meio ambiente, ainda que indiretamente. No caso In the matter of cross-border trucking services, por exemplo, o Painel concluiu que a suspensão da análise dos pedidos de licença para operação nos Estados Unidos para os caminhões pertencentes a prestadores de serviço do México violava as obrigações contidas no Anexo I (reservas a medidas de livrecomércio já existentes ou a comprometimentos de liberalização), no artigo 1202 (tratamento nacional a serviços transfonteiriços), e artigo 1203 (tratamento da nação mais favorecida para serviços transfronteiriços) do NAFTA. Os Estados Unidos alegaram que a medida se justificava pela falta de segurança dos caminhões provenientes do México, mencionando, ainda, pelo menos dois acidentes que envolviam caminhões do México (em um deles, os freios não funcionavam adequadamente e os pneus apresentavam alto desgaste) e que resultaram em derrame de materiais perigosos. O Painel rejeitou os argumentos dos Estados Unidos, alegando que "as inadequações do sistema de regulamentação do México não forneciam base jurídica suficiente para os Estados Unidos manterem a moratória". ${ }^{22}$

Finalmente, a Comissão para a Cooperação Ambiental (Commission for Environmental Cooperation), criada pelo Acordo de Cooperação Ambiental da América do Norte (North American Agreement on Environmental Cooperation), tem como principal foco a aplicação das regulamentações ambientais. ${ }^{93}$ Os mecanismos de solução de controvérsia estão previstos nos artigos 13, 14, 15 e 22 a 36 . Até o presente momento, poucos casos foram decididos com base nos dispositivos do artigo $13,{ }^{94}$ os quais se destinam a controvérsias outras que aquelas originadas pela falha do Estado em aplicar as leis ambientais. Por outro

91 S.D. Myers, Inc. v. Canada Partial Award, PP. 136, 667 (Nov. 13, 2000), disponivel em http://www.naftaclaims.com.

92 In the Matter of Cross-Border Trucking Services (USA-Mex), February 6 (2001), 12. 93 Isso se deve à pouca aplicação dos padrões e regulamentos ambientais no México. Kal Raustiala, International "Enforcement of Enforcement" Under the North American Agreement on Environmental Cooperation, 36 VA. J. INT'L L. 721, 723, 728-29(1996). 94 Ignacia Moreno et al. Free Trade and the Environment: The NAFTA, the NAAEC, and Implications for the Future, 12 TUL. ENvTL. L.J. 405, 431 (1999). 
lado, até o ano de 2000, mais de vinte reclamações foram entregues, com base nos procedimentos dos artigos 14 e 15.95 A Comissão pode, ao final, elaborar um "relatório dos fatos" (factual record), isto é, um relatório preparado por especialistas independentes, sem caráter vinculativo. ${ }^{96}$

Finalmente, os mecanismos de solução de controvérsia dos artigos 22 e 36 somente podem ser usados caso um estado persistentemente falhe na aplicação de suas normas ambientais. ${ }^{97} \mathrm{O}$ primeiro passo é a consulta entre as partes envolvidas e, caso não se chegue a um consenso, o procedimento seguinte é a arbitragem. ${ }^{98}$ Até o presente momento, nenhuma arbitragem foi iniciada, e muitos vêem tais artigos como letra morta, já que as partes ficariam "relutantes em partir para um procedimento judicial para solucionar controvérsias internacionais envolvendo o meio ambiente". ${ }^{99}$

\section{A JURISDIÇÃO CONCORRENTE DE TRIBUNAIS INTERNA- CIONAIS E A PROTEÇÃO AO MEIO AMBIENTE}

\section{A) Mecanismos de solução de controvérsias internacionais}

1. Classificação dos mecanismos de solução de controvérsias

Um litígio internacional pode se dar entre Estados (ou entre Estados e organizações intergovernamentais ou, ainda, entre elas próprias), sendo regido pelo Direito Internacional Público; entre pessoas físicas ou jurídicas, de direito público ou privado, submetidas a sistemas jurídicos nacionais distintos; ou entre pessoas físicas ou jurídicas de direito interno dos Estados, de um lado, e Estados, de outro. No segundo caso, a solução pode ser judicial, sendo regida pelo Direito Internacional Privado, ou extrajudicial. O último caso, por fim, pode ter solução perante o Poder

95 Jonathan S. Blum. The FTAA and the Fast Track to Forgetting the Environment: a comparison of the NAFTA and the MERCOSUR Environmental Models as Examples for the Hemisphere. 35 TEX. INT'L L.J. 435, 453 (Summer 2000).

96 North American Agreement on Environmental Cooperation, Sep. 13, 1993, 32 I.L.M. 1480,1490 art. 15.

$97 \mathrm{Id}$. arts. 22-36.

98 Jonathan S. Blum, The FTAA and the Fast Track to Forgetting the Environment: a comparison of the NAFTA and the MERCOSUR Environmental Models as Examples for the Hemisphere. 35 TEX. INT'L L.J. 435.453 (Summer 2000).

99 John Knox. A new approach to compliance with international environmental law: the Submissions procedure of the NAFTA environmental commission, 28 ECOLOGY L.Q. 1 (2001). 
Judiciário do Estado envolvido ou, no âmbito do Direito Internacional Público, ter uma solução em instituições especializadas. ${ }^{100}$

Os modelos de sistemas para solução de controvérsias entre Estados podem ser classificados em dois padrões: ${ }^{101}$ o tradicional, de alcance maior e em que prevalece uma finalidade política, e o econômico, de menor alcance e com finalidade fundamentalmente econômica. O primeiro estabelece oficialmente como regra de direito internacional a solução pacífica de disputas, a qual pode ser estabelecida em acordo (resultante de negociações, bons ofícios, mediação, conciliação ou comissão de inquérito) ou em sentença internacional (arbitragem ou tribunal internacional). Já o segundo padrão prima pelo cumprimento de normas livremente acordadas pelas partes sobre seu comércio exterior, sendo apenas secundária a finalidade de assegurar paz resguardando a soberania. O modelo é mais flexível, com regras complexas e não decorrentes de procedimentos jurídicos. Pode envolver consultas, negociações e arbitragem, tendo como exemplos os sistemas de solução de controvérsias do GATT (hoje OMC), do NAFTA e do Mercosul. ${ }^{102}$

Ainda, os mecanismos de solução de controvérsias no Direito Internacional Público podem ser divididos em duas categorias: mecanismos diplomáticos (métodos não-jurisdicionais) e mecanismos jurisdicionais. Os primeiros não possuem foro especializado e independente, sendo instrumentalizados por negociação direta, sistemas de

100 SOARES, Guido F.S. Solução e prevenção de litígios internacionais: tipologia e características atuais. in MERCADANTE, Araminta de Azevedo; MAGALHÃES, José Carlos (coord.). Solução e Prevenção de Litígios Internacionais - Volume II. São Paulo: NECIN-CAPES; Porto Alegre: Livraria do Advogado, 1999. p. 15-16.

101 Guido Soares, porém, entende sem relevância a distinção entre, de um lado, litígios de natureza política ou jurídica e, de outro, de natureza econômica, por entender que, embora esses últimos tenham um encaminhamento com maior precisão e eficácia, tal se deve não pela natureza do assunto tratado, mas sim da natureza da regulamentação das relações interestatais nas organizações que prevêem tais mecanismos de solução de controvérsia. (Solução e prevenção de litígios internacionais: tipologia e características atuais. in MERCADANTE, Araminta de Azevedo; MAGALHÃES, José Carlos (coord.). Solução e Prevenção de Litígios Internacionais - Volume II. São Paulo: NECIN-CAPES; Porto Alegre: Livraria do Advogado, 1999. p. 14). Independentemente da importância de tal distinção, é fato que ela existe, seja baseada na natureza do assunto discutido, seja com base na relação interestatal verificada.

102 BAPTISTA, Luíz Olavo. Sistemas para Solução de Divergências nas Instituições de Integração e o Mercosul. in MERCADANTE, Araminta de Azevedo; MAGALHÃES, José Carlos (coord.). Solução e Prevenção de Litígios Internacionais - Volume II. São Paulo: NECIN-CAPES; Porto Alegre: Livraria do Advogado, 1999. p.441-453. 
consultas, intervenção de um terceiro (mediador ou conciliador) e painéis de especialistas. Buscam não necessariamente a recomposição da ordem jurídica violada, mas sim a composição de interesse das partes conflitantes. Já nos mecanismos jurisdicionais, que visam a uma solução baseada em uma regra de Direito, há necessariamente a intervenção de um terceiro alheio ao conflito, seja ele um árbitro (arbitragem) ou um juiz (corte de justiça). ${ }^{103}$

\section{Conflitos de jurisdição entre} mecanismos de solução de controvérsias internacionais: as normas reguladoras de conflito (competitionregulating norms)

A discussão acerca da "proliferação" de mecanismos internacionais de solução de controvérsias não é tão recente como pode parecer à primeira vista, e mesmo em períodos mais antigos do Direito Internacional, a doutrina já demonstrava alguma preocupação com relação ao tema. ${ }^{104} \mathrm{~A}$ fim de regulamentar a escolha do órgão decisório, dois modelos foram adotados: a cláusula de exclusão jurisdicional (vedando o litígio em outros órgãos), que tanto pode conter dispositivos flexíveis quanto inflexíveis (dependendo da capacidade da parte de afastar a jurisdição de um determinado órgão), e a jurisdição nãoexclusiva (permitindo a eleição do foro pelas partes), que inclui a organização jurisdicional paralela e a residual (dependendo do nível de precedência que o mecanismo em questão tem sobre as demais jurisdições concorrentes). ${ }^{105}$

A OMC, por exemplo, apresenta um dispositivo de jurisdição exclusiva inflexível, ${ }^{106}$ pois o artigo 23 do Entendimento Relativo às Normas e Procedimentos pelos quais se rege a Solução de Diferenças que forma parte do acordo sobre a OMC veda a apresentação de casos sobre os acordos da OMC em qualquer outro órgão que não aquele estabelecido pelo próprio acordo sobre a OMC. ${ }^{107}$

Ao contrário, o dispositivo de solução de controvérsias contido na Convenção das Nações Unidas sobre o Direito do Mar (United Nations Convention on the Law of the Sea UNCLOS) ${ }^{108}$ consiste em uma cláusula

103 FRANCESCHINI DA ROSA, Luis Fernando. Mercosul e função judicial: realidade e superação. São Paulo: LTr, 1997. p. 35.

104 Veja por todos. Charney, Jonathan I. Is international law threatened by multiple international tribunals? Recueil des Cours, Volume 271 (1998), pp. 101-382.

105 Yuval Shany. The Competing Jurisdiction of International Courts and Tribunals. 180 (Oxford ed. 2003).

$106 \mathrm{ld}$, at 183 .

107 Entendimento Relativo às Normas e Procedimentos pelos quais se rege a Solução de Diferenças que forma parte do Acordo sobre a OMC, art. 23.

108 United Nations Convention on the Law of the Sea of 10 December 1982. 
de jurisdição não-exclusiva residual, ${ }^{109}$ pois o artigo 282 da referida Convenção não só permite que a disputa seja apresentada em outra jurisdição, mas também impede a aplicação dos mecanismos presentes na UNCLOS caso as partes tenham concordado, através de acordo geral, regional ou bilateral, que suas controvérsias sejam submetidas a outro procedimento que gere decisão dotada de caráter vinculante. ${ }^{110}$

Portanto, em um caso no qual tanto o mecanismo de solução de controvérsias do GATT/OMC quanto o Tribunal Internacional de Direito do Mar (Tribunal do Mar) tenham "jurisdição", aquele teria precedência, segundo o modelo apresentado. Entretanto, essa posição não é pacífica, uma vez que a "cláusula de não-derrogação" expressa no artigo 311(3) da UNCLOS ${ }^{111}$ é considerada suficiente para tornar "inválida" norma conflitante de tratado posterior (como no caso do GATT/ OMC). ${ }^{112}$ Assim, independentemente da existência de mecanismos de solução de controvérsias do GATT/OMC, o Tribunal do Mar ainda permaneceria com jurisdição. ${ }^{113}$

A questão fica mais complexa quando a jurisdição da CIJ concorre com a determinada pela UNCLOS. A CIJ apresenta uma jurisdição nãoexclusiva paralela, isto é, ao mesmo tempo que seu estatuto permite o recurso a outros mecanismos de solução de controvérsias, ele (diferentemente da UNCLOS) não se sujeita a tais mecanismos. ${ }^{114}$ Isso significa dizer que, ainda que seja possível a escolha de outro foro, a CIJ

109 Yuval Shany. The Competing Jurisdiction of International Courts and Tribunals. 201-02 (Oxford ed. 2003).

110 UNCLOS, art. 282. "If the States Parties which are parties to a dispute concerning the interpretation or application of this Convention have agreed, through a general, regional or bilateral agreement or otherwise, that such dispute shall, at the request of any party to the dispute, be submitted to a procedure that entails a binding decision, that procedure shall apply in lieu of the procedures provided for in this Part, unless the parties to the dispute otherwise agree."

111 UNCLOS, art. 311 , o qual impede as partes de estabelecer acordos futuros que se mostrem incompativeis com a natureza da UNCLOS ou que, de alguma outra forma, derrogue seus princípios básicos.

112 Veja Lakshman D. Guruswamy, Should UNCLOS or GATT/WTO decide trade and environment disputes?, 7 MINN. J. GLOBAL TRADE 287, 305-6. (argumentando que o GATT/ OMC não é o foro apropriado para as controvérsias envolvendo o meio ambiente, por não reconhecer "a proteção ambiental marítima como princípio básico" - "it does not recognize maritime environmental protection as a basic principle").

$113 \mathrm{Id}$. at 305-6.

114 Veja U.N. Charter arts. 33, 95. Veja também Yuval Shany. The Competing Jurisdiction of International Courts and Tribunals. 195-96 (Oxford ed. 2003). 
não deixa de ter jurisdição, nem impede o recurso posterior aos seus procedimentos jurisdicionais. Considerando que tanto a CIJ quanto o Tribunal do Mar têm jurisdição para decidir sobre a interpretação ou aplicação da UNCLOS, muitos viam a criação do Tribunal do Mar com reservas. ${ }^{115}$ Nessa situação de conflito, porém, os dispositivos da UNCLOS e do Estatuto da CIJ poderão esclarecer alguns pontos quanto aos casos de jurisdição concorrente. Por exemplo, como a declaração a que se refere o artigo 36 (2) do Estatuto da CIJ pode ser considerada como um "acordo" para o propósito do artigo 282 da UNCLOS, o Tribunal do Mar não teria jurisdição. ${ }^{116}$

A CEDH, por sua vez, é considerada como detentora de uma jurisdição exclusiva flexível, porquanto o artigo 55 da Convenção Européia de Direitos Humanos estabelece a jurisdição compulsória da CEDH, a qual só pode ser afastada mediante acordo especial realizado entre as partes. ${ }^{117}$ Finalmente, os procedimentos do NAFTA são considerados um "meiotermo" entre os dois modelos supracitados, permitindo uma eleição restrita do foro. ${ }^{118}$ Prevendo os possíveis conflitos entre o NAFTA e o GATT/OMC, os autores do projeto do NAFTA buscaram coordenar a jurisdição de ambos os órgãos ao estabelecer, no artigo 2005, que, no caso de uma disputa que se enquadrasse na jurisdição de ambos, a parte autora poderia escolher onde litigar. ${ }^{119}$ Similarmente, o MERCOSUL recentemente adotou o Protocolo de Olivos, o qual contém uma previsão semelhante

115 Veja por todos, Shigeru Oda. Some Reflections on the Dispute Settlement Clauses in the United Nations Convention on the Law of the Sea, in ESSAYS IN INTERNATIONAL LAW IN HONOR OF Judge MANFRED LACHS 645, 649 (J. Makarcyzyk ed. 1984). O Juiz da CIJ afirma que o desenvolvimento uniforme de uma jurisprudência internacional seria melhor atingido com o fortalecimento da CIJ, e não com a dispersão da função judicial internacional em vários órgãos esparsos ("the rule of law based upon the uniform development of jurisprudence will be best secured by way of strengthening the role of the International Court of Justice, not by dispersing the judicial funcion of the international community among various scattered organs").

116 Veja Tullio Treves. Conflicts Between the International Tribunal for the Law of the Sea and the International Court of Justice, 31 N.Y.U. J. INT'L L. \& PoL. 809, 812 (Summer 1999). O autor em seguida observa que essa regra é aplicável somente para as controvérsias surgidas conforme a Parte XV da Convenção, reconhecendo que, no caso de uma disputa baseada na Parte XI da UNCLOS, um real conflito de jurisdição pode surgir. See id. at 813-21.

117 Yuval Shany. The Competing Jurisdiction of International Courts and Tribunals. 188-191 (Oxford ed. 2003).

118 Id., 208-209.

119 NAFTA, art. 2005. 
à do NAFTA, permitindo ao autor escolher entre o mecanismo de solução de controvérsias do MERCOSUL e o da OMC (ou outro mecanismo de solução de controvérsias relacionado ao comércio). ${ }^{120}$

B) Possíveis soluções para a questão das disputas ambientais submetidas a múltiplas jurisdições

1. A criação de um Tribunal

Internacional do Meio Ambiente: seria uma solução?

Como visto antes, muitas disputas que tocam na questão da proteção ambiental são discutidas em órgãos especializados em outros assuntos específicos, como comércio ou direitos humanos. Isso não significa afirmar que o meio ambiente não tem relação com o comércio, ${ }^{121}$ ou que inexiste ligação entre os direitos humanos e a proteção ambiental, ${ }^{122}$ mas significa, sim, dizer que não há atualmente nenhum tribunal especificamente criado para lidar com questões ambientais.

Por esse motivo, muitos propuseram a criação de um Tribunal Internacional Ambiental para lidar especificamente com disputas de direito ambiental. ${ }^{123}$ Entretanto, essa proposta apresenta um problema similar ao apontado em diversos casos decididos por mecanismos de solução de controvérsias ligados ao comércio: em um órgão especializado, um assunto seria, em última instância, subordinado ao outro, tornando, portanto, mais difícil uma abordagem mais equilibrada entre interesses conflitantes. ${ }^{124}$

\section{Fortalecendo a Corte Inter-} nacional de Justiça como meio de garantir uma proteção ambiental mais efetiva

A CIJ apresenta uma vantagem, uma vez que as fontes que a mesma utiliza para basear seus julgamentos incluem,

120 Protocolo de Olivos para a Solução de Controvérsias no Mercosul, 18 Fev. 2002, art. 1(2). Veja por todos, Eduardo Biacchi Gomes. Protocolo de Olivos: alterações no sistema de soluções de controvérsias do Mercosul e perspectivas, 42 Revista de Direito Constitucional e Internacional 78-88 (Jan./Mar. 2003).

121 Veja Report of the Committee on Trade and Environment, WT/CTE/1, Nov. 12, 1996, e anos seguintes, disponivel em www.wto.org; mas veja também David W. Leebron, Symposium: The Boundaries of the WTO: Linkages, 96 A.J.I.L 5 (Jan. 2002).

122 John Lee, The Underlying Legal Theory to Support a Well-Defined Human Right to a Healthy Environment as a Principle of Customary International Law, 25 COLUM. J. ENvTL. L. 283 (2000); Gabcikovo-Nagymaros Project (Hung. v. Slovakia), 1997 I.C.J. 7, 206 (Sep. 25) (dissenting opinion of Judge Weeramantry).

123 Veja por todos, ElLEN Hey. Reflections on an international environmental court (Kluwer Law International ed. 2000).

124 Jeffrey L. Dunoff. Institutional Misfits: the GATT, the ICJ \& Trade-environment Disputes, 15 Mich. J. INT'L L. 1043, 1108 (Summer 1994). 
com o mesmo status, tanto normas de direito ambiental quanto as demais normas de direito internacional. A utilização, entretanto, de mecanismos jurisdicionais para casos de direito internacional ambiental não parece ser a opção mais indicada, principalmente no caso da CIJ.

Primeiramente, a ausência de jurisdição compulsória da CIJ, o baixo número de vezes em que os estados confiam as suas disputas à corte, associados ao tempo relativamente longo que se leva até uma decisão, torna questionável a efetividade de tal instituição para as questões ambientais. Outrossim, não há consenso quanto a dois pontos fundamentais, quais sejam: os modos de reparação que podem ser buscados em caso de danos ambientais; e quais entes teriam legitimidade para fazer isso. Finalmente, a impossibilidade de haver mais participação pública nas decisões da CIJ também poderia afetar negativamente o objetivo da proteção ambiental, uma vez que a sociedade civil tem um papel ativo na busca da proteção ao meio ambiente. ${ }^{125}$

\section{CONCLUSÃO}

Um estudo da ONU compara as questões ambientais com problemas de trânsito: é mais útil instalar semáforos, estabelecer regras de tráfego e outros meios de controle do que colocar tais medidas em segundo plano para se concentrar na responsabilização de cada motorista pelos danos causados aos demais. ${ }^{126} \mathrm{Da}$ mesma forma, a proteção ambiental é melhor atingida através da cooperação entre os Estados, e não com mecanismos jurisdicionais, que dificilmente preveniriam danos ambientais, mas sim se concentrariam na reparação de danos passados. ${ }^{127}$

Entretanto, a cooperação entre os Estados pode ainda assim se mostrar insuficiente para enfrentar todos os aspectos da proteção ao meio ambiente. Nesses casos, se não for obtida a cooperação, e caso não se chegue a nenhum consenso, somente então, o mecanismo jurisdicional deveria ser buscado. Pela análise das decisões de diferentes organismos, é possível concluir que aquele que melhor versa sobre as questões ambientais seria a CIJ. É inegável que nos casos em que a CIJ teve a oportunidade de lidar com princípios do direito internacional ambiental, ela focou-se nas "áreas específicas do direito internacional que não se relacionavam com o meio

125 Para uma análise mais aprofundada de tais argumentos, veja Jeffrey L. Dunoff, Institutional Misfits: the GATT, the ICJ \& Trade-environment Disputes, 15 Mich. J. INT'L L. 1043, 1085-1106(Summer 1994).

126 UNITAR. International Co-operation for Pollution Control, Research Reports 9, 25 (1972).

127 Para mais argumentos nesse sentido, veja Franz Xaver Perrez. Cooperative Sovereignty - From Independence to Interdependence in the Structure of International Environmental Law (Kluwer Law International ed. 2000), 255-283. 
ambiente em si". ${ }^{128}$ Entretanto, o crescente número de casos da $\mathrm{CIJ}$ fazendo referência a princípios de direito internacional ambiental, juntamente com os pedidos das partes levantando tais argumentos, as diversas opiniões separadas ou dissidentes de juizes defendendo especificamente uma maior preocupação com o meio ambiente, e a criação de um Chamber para Questões Ambientais, constituem fatores relevantes para considerar a $\mathrm{CIJ}$ o foro apropriado para as disputas ambientais.

Contudo, alguns obstáculos permanecem. Como visto, a jurisdição da CIJ, além de voluntária, é não-exclusiva. Portanto, ela não pode impedir as partes de procurar outros tribunais ou órgãos para a solução de sua controvérsia. Além disso, o conflito de jurisdições permaneceria como um entrave na busca de uniformidade e certeza nas decisões internacionais.

Sendo assim, uma possibilidade para enfrentar tais limitações seria o estabelecimento de um órgão geral e permanente de apelação - e a CIJ poderia desempenhar esse papel. ${ }^{129}$ Para isso, algumas mudanças se fariam necessárias: as regras atinentes à legitimidade (locus standi), por exemplo, deveriam ser reformuladas para se enquadrar aos propósitos de um órgão geral (ou "universal") de apelação.

Embora isso possa parecer relativamente idealista no presente momento, essa estrutura é viável, e melhoraria o sistema internacional de mecanismos jurisdicionais de solução de controvérsias, o que, em última análise, afetaria positivamente as disputas envolvendo questões ambientais. Analogamente, embora nas décadas passadas a responsabilidade internacional do indivíduo, juntamente com o estabelecimento de um Tribunal Penal Internacional, fossem consideradas soluções utópicas, tais medidas são hoje uma realidade no campo do Direito Internacional. Do mesmo modo, o estabelecimento de um órgão de apelação internacional, permanente e geral, poderia - e deveria - se tornar uma realidade no futuro desenvolvi-mento do Direito Internacional.

128 Ian Brownlie. Principles of Public International Law. 274 (Oxford 6. ed. 2003).

129 Para mais opiniões favoráveis a essa proposta, veja Charney, Jonathan I. Is international law threatened by multiple international tribunals?, Recueil des Cours, Volume 271 (1998), p. 101-382; Yuval SHANY. The Competing Jurisdiction of International Courts and Tribunals, 272-73 (Oxford ed. 2003). 